\title{
Application Analysis of the Emergency Communication System in Weather Radar
}

\author{
Zhixing Zheng1, Ying Chen'1, Hai Cao² \\ ${ }^{1}$ Xiapu County Meteorological Bureau, Ningde, China \\ ${ }^{2}$ Fujian Provincial Meteorological Information Center, Fuzhou, China \\ Email:710721328@qq.com
}

How to cite this paper: Zheng, Z.X., Chen, Y. and Cao, H. (2018) Application Analysis of the Emergency Communication System in Weather Radar. Journal of Geoscience and Environment Protection, 6, 167-174. https://doi.org/10.4236/gep.2018.68012

Received: July 4, 2018

Accepted: August 26, 2018

Published: August 29, 2018

Copyright (c) 2018 by authors and Scientific Research Publishing Inc. This work is licensed under the Creative Commons Attribution International License (CC BY 4.0).

http://creativecommons.org/licenses/by/4.0/

(c) (i) Open Access

\begin{abstract}
According the work arrangements and requirements of carried satellite emergency communications, Fujian Meteorological Bureau establishes a satellite emergency communication system for radar stations to meet the needs of data transmission under the radar state of emergency. This paper introduces the main construction content, structure diagram, network diagram, drills and emergency communications procedures of the emergency communication system for the province's meteorological radar satellite and provides the test emergency situation of the province's meteorological radar-satellite data transmission. Satellite emergency communication system can basically meet the needs of emergency radar data transmission.
\end{abstract}

\section{Keywords}

Weather Radar, Satellite, Emergency Communications

\section{Introduction}

With the progress of society and the improvement of people's living standards, higher and higher requirements have been put forward for the meteorological spirit of "accurate, timely, innovative and dedication" in the new era. Weather radar is an important means of disaster weather monitoring and early warning. In various practices that detect the atmosphere on which humans depend, meteorological radars become disastrous weather with their high spatial and temporal resolution and timely and accurate remote sensing capabilities. In particular, it is an extremely effective tool for small and medium-scale severe weather monitoring and short-term forecasting [1]. The communication network is the basis of modern meteorology. Natural disasters cause flooding and power outages, and heavily attack the terrestrial communication network. Communication 
is a key means to guarantee emergency operations, rescue and disaster relief. Satellite communication is one of the indispensable means of emergency communication and has received the attention of all countries [2].

At present, the data transmission of the meteorological radar system in our province uses the ground communication network dedicated line provided by the fixed network operator, although the cost is relatively low, but the transmission means is single. When an emergency occurs, such as the failure of the ground link, when the radar data is urgently needed, the data transmission cannot be guaranteed. According to the construction needs of meteorological services in Fujian Province, we propose to build a satellite emergency communication system for radar stations in the province, and propose a feasible, reliable and multi-mode link guarantee mechanism for data transmission between meteorological radar stations and provincial meteorological stations, solve the problem that the radar cloud image cannot be transmitted in the event of a sudden disaster, causing power and ground communication networks, thus ensuring the real-time transmission of radar data and ensuring the forecaster's trend and forecast of future weather.

\section{Schematic Diagram of Satellite Communication Structure}

The satellite communication system is mainly composed of a satellite transponder and a communication earth station (Figure 1). The communication satellite is a microwave relay station located in the air, and the communication system in the satellite is called a satellite transponder. Its main function is to receive low-noise amplification after receiving the signal from the ground, then perform power amplification, and then send it back to the ground. The communication earth station is composed of an antenna feeder device, a transmitting device, a receiving device, a communication device, and communication software, and is used for transmitting and receiving a carrier [3].

The satellite communication system related to emergency communication is classified into the fixed satellite service FSS (Fixed Satellite Service), the mobile satellite service MSS (Mobile Satellite Service), and the satellite short message communication. The currently used FSS is the VSAT satellite communication technology. Most of the VSAT satellite communications use the Earth's equatorial geosynchronous orbit (GEO, 35,786 km above the equator) communication satellites, mainly used in multimedia two-way communication systems, broadcast and television signal relay systems, etc., rarely used for personal communication. VSAT satellite communication is often a private network system with good security and catastrophic resistance, so it is always chosen as a means of emergency communication.

There are many VSAT satellite communication technologies. From the perspective of network construction, they are mainly divided into three categories: point-to-point, mesh-shaped network, and star-shaped network.

The satellite communication system of this project adopts a star topology 
( $\mathrm{S} 4120 \mathrm{H}$ is a low-cost satellite communication machine based on star network). As shown in the figure below, satellite ground stations, including indoor units and outdoor antennas, are established at each radar station, and a central station is established in the provincial center to realize data transmission via satellite.

The specific data delivery route is:

Radar station satellite ground station $\leftrightarrow$ satellite $\leftrightarrow$ provincial center, Emergency communication vehicle portable satellite ground station $\leftrightarrow \rightarrow$ satellite $\leftarrow$ provincial center.

\section{Vehicle Satellite Communication System}

In recent years, a series of public emergencies such as floods and droughts, snowstorms, earthquakes, production and other environmental accidents have occurred frequently, improving the ability to prevent and handle public emergencies, and quickly constructing satellite communication networks at the scene of emergencies [4]. It is an important guarantee for handling incidents quickly.

A single-box portable satellite station (hereinafter referred to as the product) can meet this demand. The product is highly maneuverable, flexible and off-road, and is able to reach the forefront of the scene in time. The communication satellite and the satellite communication command vehicle are used to establish a sudden on-site information collection satellite communication network, and the communication link is constructed at the emergency scene and the event handling command center, and data, voice and video can be mutually communicated. The command center can understand the first-hand situation of the scene in real time, organize the resource transfer, and quickly dispose of it to achieve the goal of least loss [5].

\section{Main Content of Project Construction}

Construction of satellite emergency communication system for radar stations in the province: Establish 8 satellite radar communication stations (including under construction) in the province; establish satellite central stations and portable satellite emergency communication vehicles in the provincial meteorological information center; and rent satellite links to meet emergency communication needs.

Each radar station and meteorological information center respectively set up a satellite ground station to communicate by satellite link (Figure 2). The data stream can be connected to the meteorological bureau through the satellite communication service provided by the operator. The central station and the radar station satellite terminal are directly connected to the local area network, and adopt the unified IP address of the whole province; the emergency vehicle is connected to the in-vehicle PC terminal to realize real-time data transmission.

Daily data transmission uses ground dedicated lines. The use of satellite links in the event of a serious natural disaster causing ground communication 


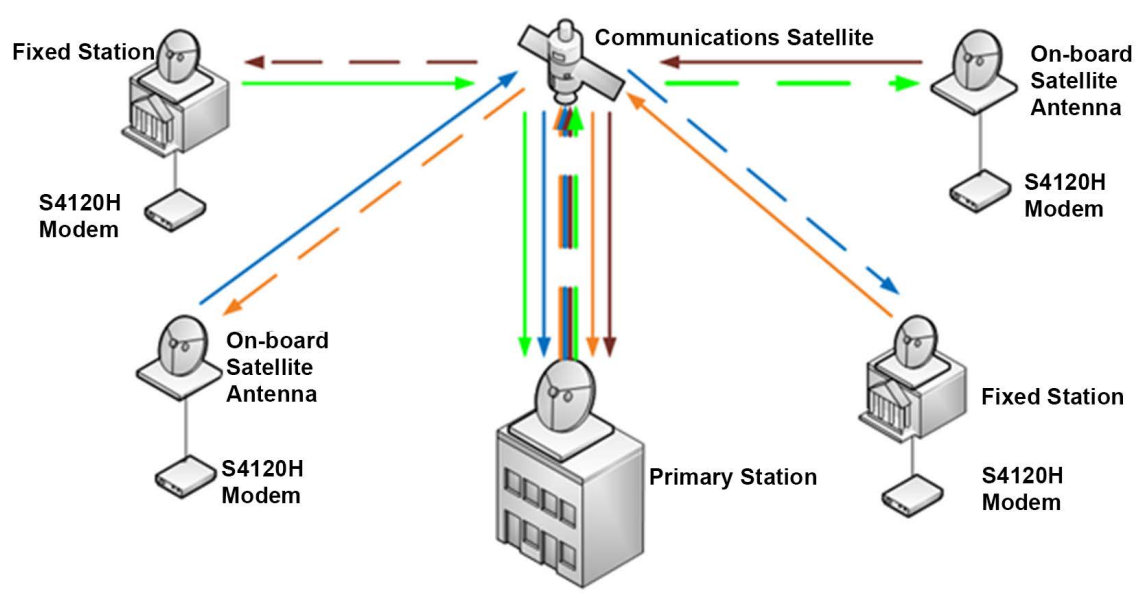

Figure 1. Schematic diagram of satellite communication structure.

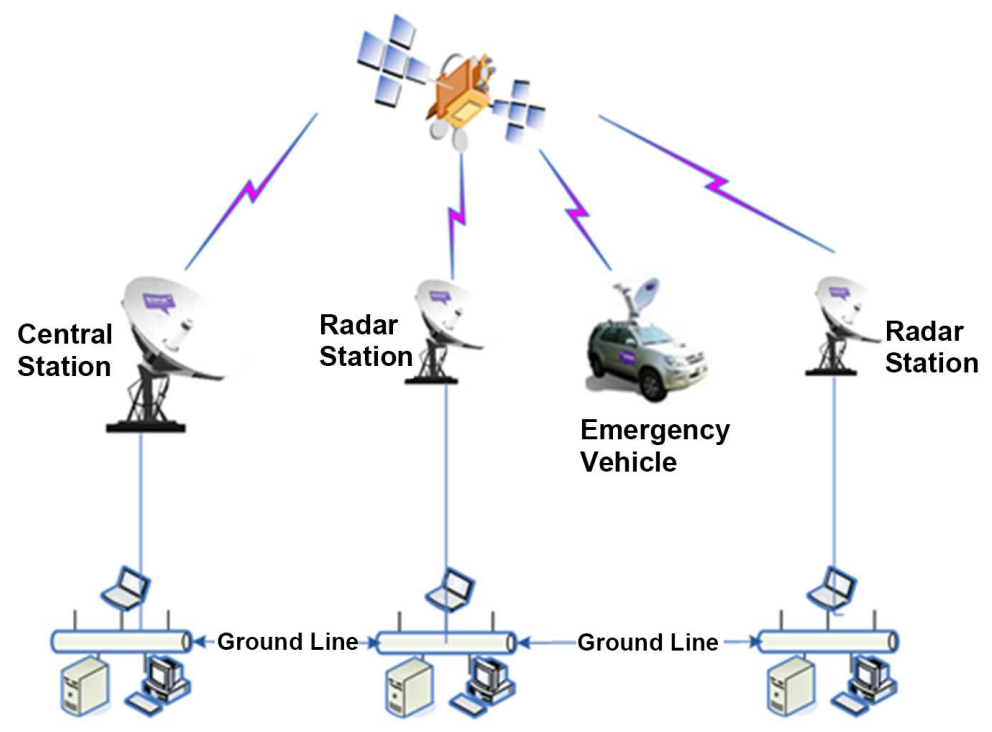

Figure 2. Satellite emergency communication structure.

disruption. The network uses VPN to establish a channel between the radar station and the weather station to ensure data security and bandwidth stability.

\section{Satellite Emergency Communication System Design}

\subsection{Functional Design of Satellite Emergency Communication System}

The satellite emergency communication bandwidth resources are rich, up to 128 Kbps - $2 \mathrm{Mbps}$, the disaster resistance is very strong (not subject to the ground environment), and the network is stable. At the same time, using satellites independently developed by China, satellite network security is strongly guaranteed. The construction of the project includes: renting and sharing $512 \mathrm{M}$ bandwidth satellite bandwidth (upgraded to $2 \mathrm{M}$ if necessary to meet the requirements of real-time emergency communication). The existing satellite bandwidth is bidi- 
rectional transmission, and $512 \mathrm{~K}$ bandwidth is maintained at normal times to maintain connectivity.

1) The satellite communication line belongs to the emergency communication line. When the terrestrial network is interrupted, first power up the satellite communicator and router and check if the line connection is normal.

2) After the self-test of the satellite communication machine is completed, if it can be spelled out and the delay is normal, it indicates that the line switching is successful and data transmission can be performed.

3) Note: Remember not to open the satellite link and the ground link at the same time. The satellite link is used up and the satellite link must be disconnected after the ground link is restored. The disconnection method will power off the satellite communicator.

\subsection{Satellite Communication Network Structure}

The construction of the heaven and earth integrated multi-channel transmission platform (referred to as the Tiandi integrated platform) is a kind of intelligent device that integrates various communication means. It is characterized by support for satellite transmission links, users can freely switch back and forth between ordinary ground lines and satellite links, or can be controlled by a preset priority order and automatically switch.

The Tiandi integrated platform organically combines satellite communication and terrestrial network communication, and undergoes strict compatibility testing and stability testing to avoid various problems that users will encounter when building their own platforms. Take the Changle radar station in Figure 3 as an example. The network structure of other radar stations is the same, and the yellow line is the satellite link map. The red line is the daily ground link map (Figure 3).

\section{Satellite Emergency Communication Application}

\subsection{Emergency Communication Drill Steps}

The drill was conducted in accordance with the following steps (Figure 4).

Step 1: Each radar station checks the status of the satellite communication machine. Usually, the communication machine is in the power-off state, and the satellite communication machine is powered on during the emergency. Observe that the two lights of the communication panel TX and RX are on, indicating that the communication machine is working normally. The network cable can also be used to connect to the computer and the communication machine, and $\log$ in to the communication machine to check the working status. But the computer IP and the communication machine should be set to the same network segment.

Step 2: Disconnect the fiber interface of the radar station ground communication link. At this time, the ground station router automatically switches the route 


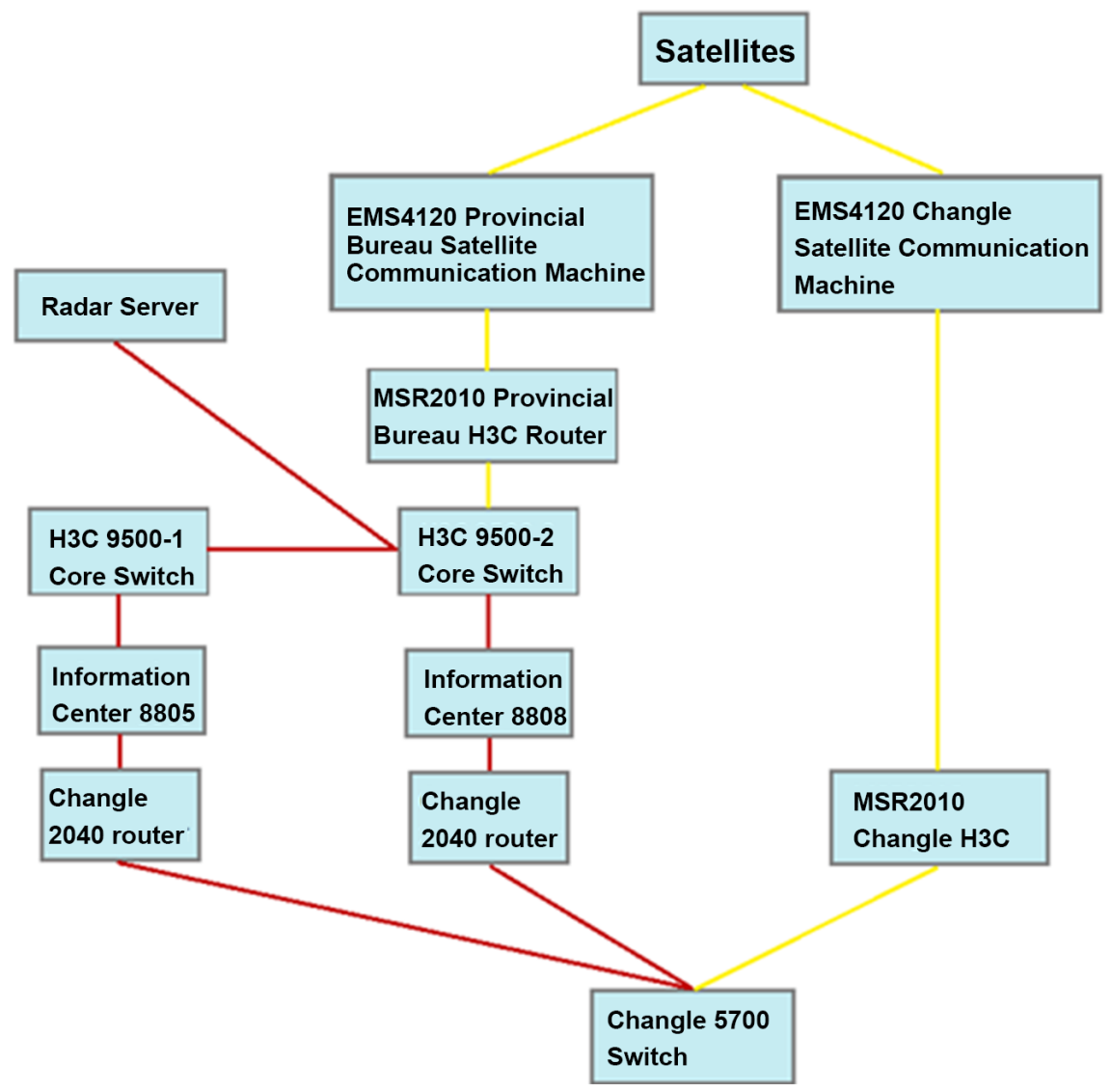

Figure 3. Radar station satellite communication network structure.

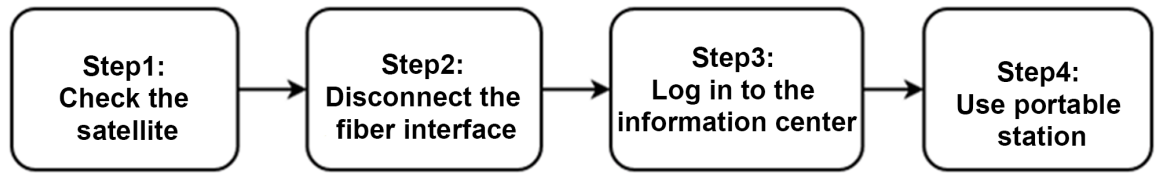

Figure 4. Emergency communication drill steps.

to the satellite channel to establish a satellite link connection with the provincial central station.

Step 3: $\log$ in to the information center radar server address 10.140.X.X on the radar station intranet computer. If it can be connected and the delay is around $1300 \mathrm{~ms}$, then the satellite link has been established.

Step 4: Use the portable station. When the ground communication link of the radar station is interrupted and the satellite ground station is unavailable, the emergency satellite communication portable station is enabled to realize the radar product data and the base data to the provincial information center data transmission.

\subsection{Transmission Software}

The satellite emergency communication data transmission software can use FileZilla software [6]. FileZilla is a fast, trusted FTP client and server-side open 
Table 1. Statistics of satellite emergency communication data transmission test in the provincial meteorological radar station.

\begin{tabular}{|c|c|c|c|c|}
\hline \multirow{2}{*}{ Radar station name } & \multirow{2}{*}{$\begin{array}{l}\text { Use satellite link to transmit } \\
\text { start and end time }\end{array}$} & \multicolumn{3}{|c|}{ Data Transmission/Arrival Situation } \\
\hline & & Base data & Product & Jigsaw \\
\hline $\begin{array}{l}\text { XX radar station } \\
\text { (August 12) }\end{array}$ & $11: 00-14: 50$ & $\begin{array}{l}19.5 \mathrm{M} \text { data is transmitted at } 11: 34 \\
\text { and received at } 11: 38 \\
19.7 \mathrm{M} \text { data is transmitted at } 14: 14 \\
\text { and received at } 14: 19\end{array}$ & $\begin{array}{l}233 \text { products } 437 \mathrm{~K} \\
\text { transmitted at } 14: 45 \\
\text { received at } 14: 46\end{array}$ & $\begin{array}{l}16 \text { parts } 18 \mathrm{~K} / \text { serving, } \\
\text { transmitted at } 14: 11 \text { and } \\
\text { received at } 14: 12\end{array}$ \\
\hline $\begin{array}{l}\text { XX radar station } \\
\text { (August 12) }\end{array}$ & 13:00-14:00 & $\begin{array}{c}11.07 \mathrm{M} \text { data is transmitted at 13:12 } \\
\text { and received at 13:13 }\end{array}$ & $\begin{array}{l}1 \text { parts } 20 \mathrm{~K} \\
\text { transmitted at 13:10 } \\
\text { received at 13:11 }\end{array}$ & $\begin{array}{l}13 \text { parts } 233 \mathrm{~K} \\
\text { transmitted at 13:34 } \\
\text { received at 13:35 }\end{array}$ \\
\hline $\begin{array}{l}\text { XX radar station } \\
\text { (August 13) }\end{array}$ & $11: 00-11: 30$ & $\begin{array}{l}1 \text { copy of } 438 \mathrm{~K} \text { compressed file } \\
\text { transmitted at } 11: 23 \\
\text { received at } 11: 24 \\
1 \text { copy of } 331 \mathrm{~K} \text { compressed file } \\
\text { transmitted at } 11: 25 \\
\text { received at } 11: 26\end{array}$ & $\begin{array}{l}1 \text { parts } 20 \mathrm{~K} \\
\text { transmitted at 11:26 } \\
\text { received at 11:27 }\end{array}$ & $\begin{array}{l}1 \text { part } 19 \mathrm{~K} \\
\text { transmitted at } 11: 19 \\
\text { received at } 11: 20 \\
\quad 1 \text { parts } 18 \mathrm{~K} \\
\text { transmitted at } 11: 21 \\
\text { received at } 11: 22\end{array}$ \\
\hline $\begin{array}{l}\text { XX radar station } \\
\text { (August 13) }\end{array}$ & $11: 50-12: 30$ & $\begin{array}{c}1 \text { parts } 9.5 \mathrm{M} \\
\text { transmitted at } 12: 12 \\
\text { received at 12:19 }\end{array}$ & $\begin{array}{c}546 \text { products } 1.065 \mathrm{M} \\
\text { transmitted at } 11: 59 \\
\text { received at } 12: 00\end{array}$ & $\begin{array}{l}43 \text { parts } 735 \mathrm{~K} \\
\text { transmitted at 12:21 } \\
\text { received at } 12: 22\end{array}$ \\
\hline
\end{tabular}

source program with a variety of features and intuitive interfaces. The controllable, organized interface and simplified way of managing multiple sites make FileZilla client a convenient and efficient FTP client tool, while FileZilla server is a small and reliable FTP server software that supports FTP \& SFTP.

\subsection{Satellite Emergency Communication Test Situation}

In order to fully verify the satellite emergency communication system, the data emergency transmission test of the satellite emergency communication system of the radar station in Fujian Province was organized. The test data of some radar stations are now counted as follows. The tested data transmission rate reaches $50 \mathrm{~K} / \mathrm{S}$, and the average rate reaches $35 \mathrm{~K} / \mathrm{S}$. Some test data are shown in Table 1.

\section{Conclusions}

The satellite emergency communication system for radar station is a feasible and reliable multi-mode link guarantee mechanism. During the typhoon landing of Sudiro in 2015, the ground station communication system of Changle Radar Station was interrupted, and the satellite station communication system of the radar station played a role in time to ensure radar data transmission.

The compensation and self-backup of the satellite link in the event of rain attenuation require the rear platform (satellite master station) to compensate for the power in the event of rain attenuation, so as to achieve maximum availability.

\section{Conflicts of Interest}

The authors declare no conflicts of interest regarding the publication of this paper. 


\section{References}

[1] Li, C., Zhang, Y. and Chen, Y. (2009) Development of Meteorological Radar Networking and Network Weather Radar. Proceedings of the 26 th Annual Meeting of the Chinese Meteorological Society, Nanjing Institute of Electronic Technology, 14 October 2009, 588-592.

[2] Zhu, G.W. (2013) Looking at the US Satellite Emergency Communication from Hurricane Sandy. Satellite \& Network, 1, 62-65.

[3] Cheng, P. (2016) Analysis on the Application of Satellite Communication Technology in Civil Air Emergency Communication. Digital Communication World, 3, 1.

[4] Bai, H.M., Guo, H.P. and Gao, H.F. (2013) Application on VPN Technique in Emergency Command Vehicle. Meteorology Journal of Inner Mongolia, 2, 45-47.

[5] Jiang, C.Y., Huang, Y.Y., Xie, D. and Guo, X.J. (2013) Construction of Emergency Communication Experimental System Using Beidou Satellite. Meteorological Science and Technology, 5, 857-860.

[6] Cheng, H.M. (2011) Application of Open Source Software FileZilla Server to Set up FTP Server. China Education Network, 7, 76-77. 